Адрес статьи / To link this article: http://cat.ifmo.ru/ru/2019/v4-i1/161

\title{
Азербайджанская анимация в творчестве Фирангиз Гурбановой, её символические приёмы в студии «Бирлик»
}

\author{
Фарида Мир-Багирзаде
}

Институт Архитектуры и Искусства Национальной Академии Наук Азербайджана, Азербайджан

$$
\text { faridamb2013@gmail.com }
$$

\begin{abstract}
Аннотация. Азербайджанская анимация начала своё творческое развитие с 1936 года и продолжает её и в наше время. Одной из ярких личностей, внёсшей большую и яркую страницу на этом поприще, стала Фирангиз Гурбанова. Её основными работами с 1988 по 2014 годы считаются: «Сотвори мечту» (1979), «Джинния Маймуна» (1991), «Аквариум» (1983), «Однажды вечером» (1985), «Мама на дереве» (1986), 4 фильма «Композиция на тему...» (1989-1992); её сына - Джавида Ахадова: «Вкус доброты» (2007), «Добрый ёж» (2009), «Зловредная муха» (2011), «Рисунок в небе» (2012), «Старые часы» (2014). Она в своих анимационных фильмах одной из первых в азербайджанском кино смогла соединить анимацию с игровым кино. В её мультфильмах впервые использовались приёмы подвижной графики и подсветки изображений цветовыми фильтрами.
\end{abstract}

Фирангиз Гурбанова - заслуженный деятель искусств Азербайджана, является доцентом кафедры рисунка в Азербайджанской Государственной Академии Художеств, член жюри в международных кинофестивалях («Тофузи», 2009), а также руководит киностудией «Бирлик».

Её профессиональные фильмы разные по сюжету, тематике, выполнению композиции и приёмам анимации. Начиная с 2007 года в своих фильмах Фирангиз Гурбанова развивает лучшие методы компьютерной графики в этом жанре в своей киностудии «Бирлик», что делает её работы более успешными и интересными.

Ключевые слова: анимация, подсветка, жанр, сюжет, композиция, жюри, приз, творчество, поиск, графика, живопись, акварель, компьютер, методы, приёмы

Азербайджанская анимация начала своё творческое развитие с 1936 года и продолжает её и в наше время. Одной из ярких личностей, внёсшей большую и яркую страницу на этом поприще, стала Фирангиз Гурбанова. Фирангиз Гурбанова родилась в семье народного артиста Азербайджана Агададаша Гурбанова, а её мамой была Кюбра Гурбанова - врач по профессии, заслуженный работник Азербайджана. Хорошая творческая атмосфера в семье дала свои ростки, и юная Ф. Гурбанова решила найти своё призвание. В 1965 году, ещё обучаясь на последнем курсе Азербайджанского Государственного Художественного училища имени Азима Азим-заде, она решает продолжить своё образование во ВГИКе, чего и добивается, оказавшись зачисленной в этот институт. По окончании института она получила специальность художника-постановщика. Её наставником-педагогом в творчестве был Иосиф Шпинель. Но одарённая студентка Фирангиз Гурбанова стремилась к новым достижений в творчестве и, соответственно, знаниям по этой 
специальности. Поэтому она заинтересовалась профессионализмом своих старших однокурсников и стала ходить на их курсы, где мастерству обучали Михаил Богданов и Геннадий Мясников.

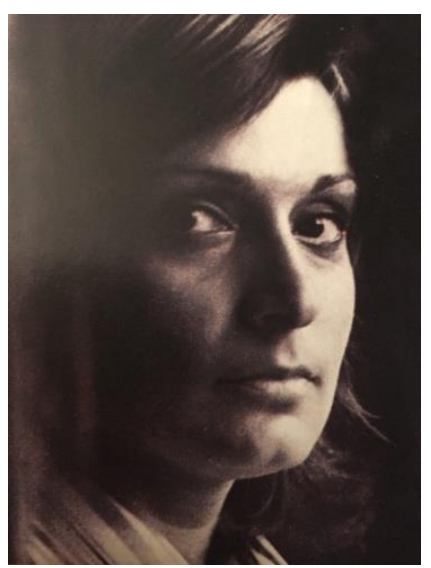

a)

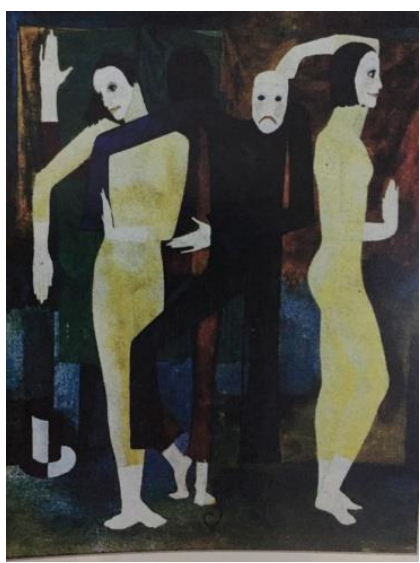

б)

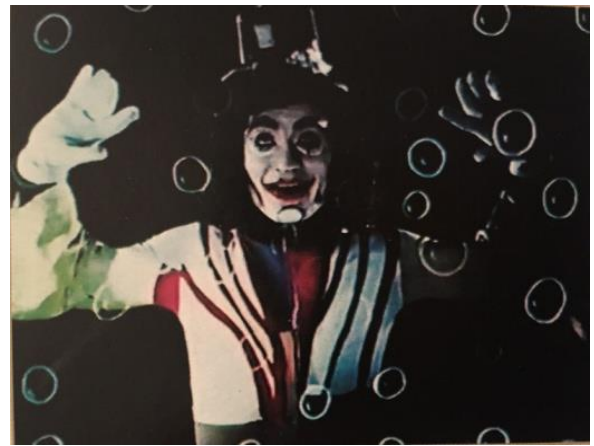

B)

Рис. 1. Фирангиз Гурбанова: а) фото; б), в) эскизы к фильму «Сотвори мечту»

Педагоги на курсах мастерства кинохудожника обучали молодую студентку умению найти собственный творческий стиль путём свободного мышления. Закончив ВГИК в 1971 году в Москве, она возвратилась на свою родину в Баку, и затем начала работать на киностудии «Азербайджанфильм». Здесь она создаёт успешные фильмы, которые в советскую эпоху становятся очень популярными. К числу этих фильмов относятся «Яблоко как яблоко» (1975), «Лев ушёл из дома» (1977), «Дачный домик для одной семьи» (1978) и т.д. Однако молодая художница ищет свои способы самовыражения и поэтому решает реализовать себя в жанре анимации. В своём дебютном фильме «Сотвори мечту» (1979) художница использует приёмы анимации. Для реализации этого фильма художница со своими материалами поехала в Москву для прохождения комиссии Государственного Комитета по кинематографии, так как в то время решение об осуществлении производства фильмов решало именно Госкино СССР. На тот момент одной из причин помех в реализации этого фильма было отсутствие у Фирангиз Гурбановой профессионального диплома режиссёра. Настойчивость, талант и умение убеждать помогли художнице в запуске этого фильма в производство. Вследствие того, что фильм был ещё новым словом в киноискусстве и анимации, его трудно было определить по жанру. Вот как отзывался о фильме кинокритик Анатолий Волков: «Тонкий поэтический этюд о клоуне, оживляющей в своём воображении образ прекрасной девушки своей мечты...Неожиданным оказался приём совмещения игры живых актёров с рисованными декорациями и куклами-марионетками» [1, с.131]. Этот фильм очень понравился Рустаму Ибрагимбекову и был показан при его содействии в Московском Доме кино.

Фирангиз Гурбанова решается снять новый фильм «Аквариум» (1983) по рассказу Чингиза Гусейнова. Так же, как и в предыдущем фильме, в нём были использованы экспериментальные приёмы анимации. Фильм был принят на киностудии «Азербайджанфильм» и был утверждён и показан в Москве, а также за рубежом, вызвав восторг у знатоков киноискусства и анимации. Его представляли на Всесоюзном кинофестивале в Киеве (1984). Он был удостоен награды на II Всероссийском конкурсе научно-популярных и документальных фильмов о защите природы в Мурманске (1984) и Диплома жюри, Почётной грамоты Государственного Кинематографического Комитета РСФСР. Идея защиты природы была выражена в привязанности мальчика к рыбкам, что можно было увидеть в сюжете этого фильма. Фирангиз Гурбанова очень умело смогла передать чувства и переживания ребёнка, его разочарование, неодобрение родителей, когда он, вернувшись после лагеря, не нашёл в аквариуме свою рыбку, а обнаружил в нём строительный материал. Мальчик всячески пытается вернуть полюбившуюся рыбку. В фильме художница применяет приёмы анимации и игрового кино. С советской делегацией аниматоров и фильмом «Аквариум» Фирангиз Гурбанова едет в города Германии (Эрфурт, Галле, Хемниц и др. города), в которых она представляет его детям, комментируя его. 


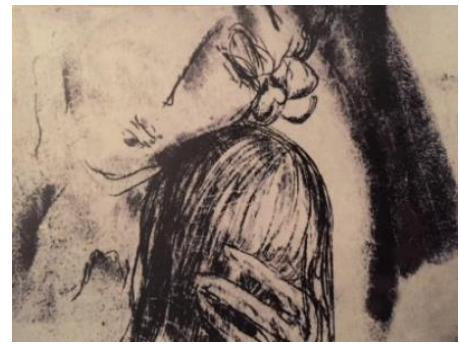

a)

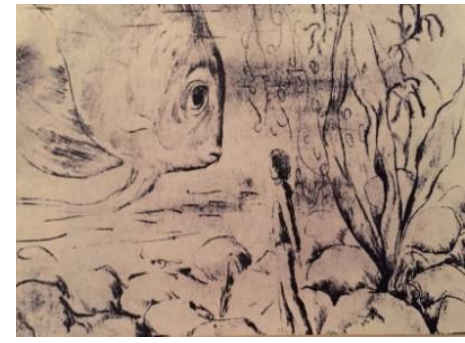

б)

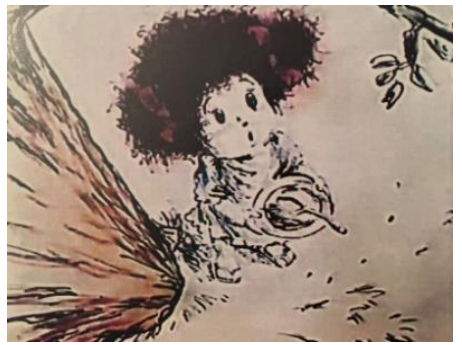

B)

Рис. 2. а) Кадр из фильма «Однажды вечером»; б) кадр из фильма «Аквариум»; в) кадр из фильма «Мама на дереве»

«Однажды вечером» (1985) является очередным фильмом Фирангиз Гурбановой, в котором она раскрывает психологию отношений матери и её 8-летней дочери. Маленькая девочка, уединившись под столом, наблюдает застолье и веселье, сопровождаемое питьём алкогольных напитков взрослыми людьми. Глазами девочки повествуется в фильме этот сюжет. Тонкая психология ребёнка, отношение её к взрослым, а также тёплое и душевное отношение матери к дочери после ухода и наступившего покоя в доме после гостей - основная линия сюжета этого фильма. Как и в предыдущих фильмах, Фирангиз Гурбанова соединяет анимацию с игровым кино. Технические приёмы анимации выполнены акварелью, музыкальное электронное сопровождение реализовано композитором Рафиком Бабаевым, которым передаётся застольное настроение.

Этот фильм был представлен на XIX Всесоюзном кинофестивале в Алма-Ате в 1986 году и получил приз жюри за лучшее и оригинальное его выполнение.

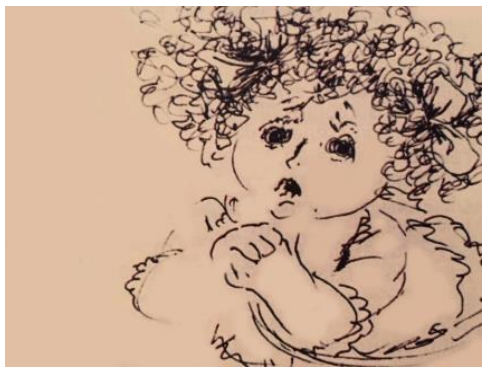

a)

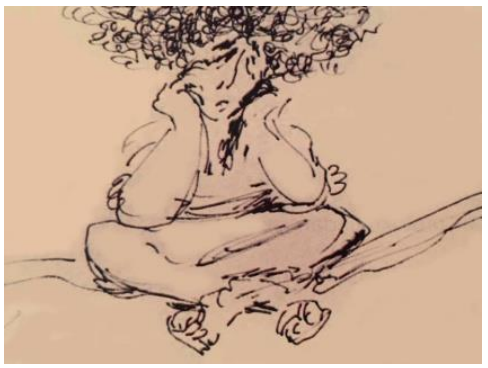

б)

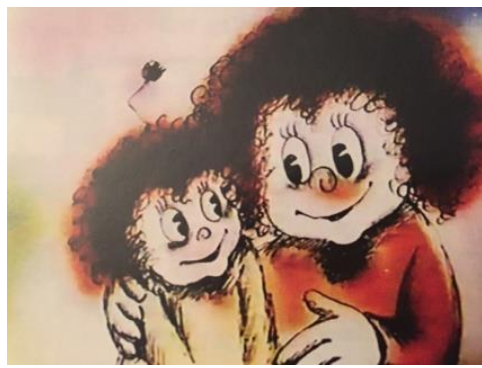

B)

Рис. 3. а), б) Раскадровки к фильму «Мама на дереве»; в) кадр из сериала «Композиция на тему...»

По сценарию Динары Сеидовой Фирангиз Гурбанова создаёт новый фильм для детей «Мама на дереве» (1986), в котором была использована в анимации классическая техника рисования тушью и пером, называемая самим автором подвижной графикой, и подсветка изображения цветовыми фильтрами. В работе с новой техникой возникали свои проблемы: «Когда заготовленная краска кончается, новая создаёт другой оттенок. Чёткость контуров нарушается, изображение при съёмке теряет своё качество, я взяла и сделала рисунок графически живым, «освободила» чёткость контуров, а в области цвета придумала новую технологию - изображение снизу освещала фильтрами. Впоследствии украинцы просили моего разрешения позаимствовать эту технику для своего фильма», — рассказывала Ф. Гурбанова $[1$, с. 4]. Как и в прежнем фильме, в основу сюжета была заложена тема, повествующая об отношении матери и дочери, несколько весёлой, по-детски наивной и в игривой форме. Фирангиз Гурбанова в сценарии затронула тему, в которой маленькая девочка не хочет есть кашу, и из-за этого её мама пытается проучить девочку и говорит ей, что будет жить на дереве в случае, если она не будет есть кашу. А, маленькая девочка представляет всё это, и зритель имеет возможность видеть своими глазами, когда мама сидит на дереве.

Этот фильм принёс Фирангиз Гурбановой успех на XX Всесоюзном кинофестивале в Тбилиси, а в 1986 году в Чехословакии состоялась его премьера в рамках культурной программы Дней СССР.

International Culture \& Technology Studies, Vol. 4, No. 1 
Фирангиз Гурбанова в 1988 году создаёт студию «Бирлик» («Единство»), которая утверждается в Москве Коллегией Госкино СССР, Секретариатом Правления Союза кинематографистов СССР и Союзом Художников Азербайджана. Студия стала снимать анимационные фильмы по заказам Министерства Культуры Азербайджана с 1988 по 2014 годы. Кроме частных, одним из первых заказов этой семейной студии стал детский фильм-сериал для Центрального Московского телевидения «Композиция на тему...», состоящий из четырёх фильмов: «Рыжик» (1989), «Король-паршивец» (1990), «Принцесса Мимо» (1991) и «День рождения〉 (1992). В основе сюжетов этих фильмов лежит победа добра над злом, воплощённая в противостоянии двух клоунов - Рыжего (доброго) и Белого (злого). В фильмах обнажаются и осуждаются не лучшие качества человека: зависть, жадность и злость, показанные на примере этих клоунов как немое кино. Музыка к фильмам Фирангиз Гурбановой была взята из написанных песен Леонидом Вайнштейном к спектаклю «Хочу купить мужа».

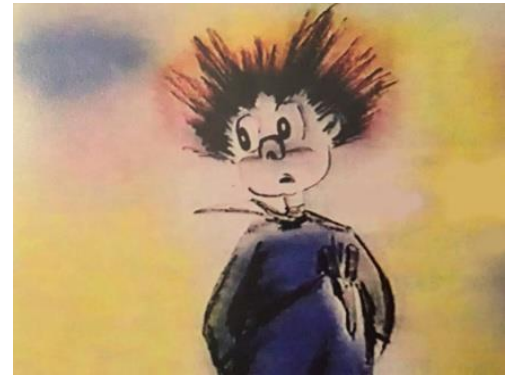

a)

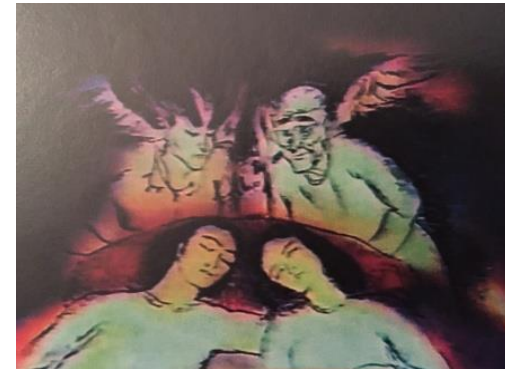

б)

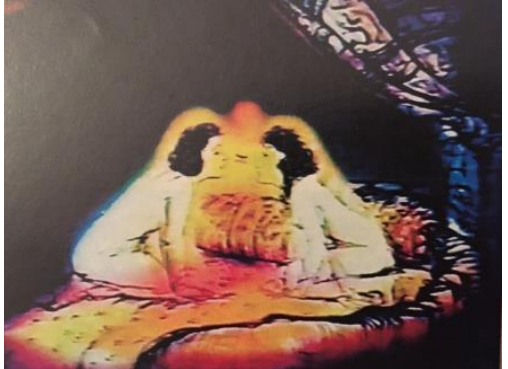

в)

Рис. 4. а) Кадр из фильма «Композиция на тему...»: б), в) кадры из фильма «Джинния Маймуна»

Фирангиз Гурбанова в 1991 году снимает рисованный анимационный фильм «Джинния Маймуна» по заказу студии «Анимационного Белорусского центра». Фильм-сказка построен по сюжетам арабских сказок «1001 ночь» и назван «Повесть о Камар-аз-Замане и Будур», в котором автором даётся её свободная интерпретация. Сказка повествует о принце Камар-аз Замане и китайской царевне Ситт Будур, в которых влюбились духи (джинны) Маймуна и Дахнаш. Эти духи спорят между собой, кто из двух молодых людей красивее всех на свете. Для сравнения их красоты Дахнаш переносит из Китая царевну Будур и укладывает её рядом со спящим Камар-азЗаманом. Уродливый джинн Кашкан решает их спор. Он превращается в блоху и по очереди кусает молодых. А они, по очереди проснувшись, влюбляются друг в друга, и по очереди засыпают вновь. Спор увенчался победой Джиннии Маймуны и Дахнаш вынужден вернуть царевну обратно в Китай. Когда же герои просыпаются, они сходят с ума от разлуки. На этом заканчивается экспозиция сказки. Дальнейшие её события повествуют о том, как влюблённые ищут друг друга, об их долгих приключениях на этом пути. Кончается сказка воссоединением влюблённых. При этом история с джиннами отходит на второй план [3, с. 187].

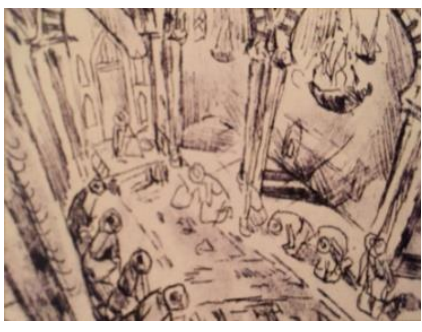

a)

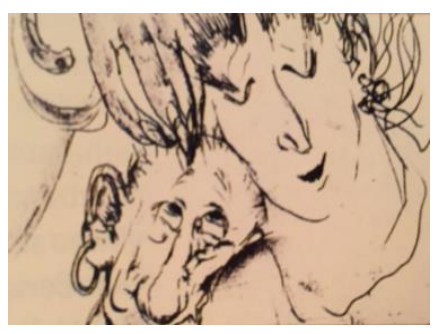

б)

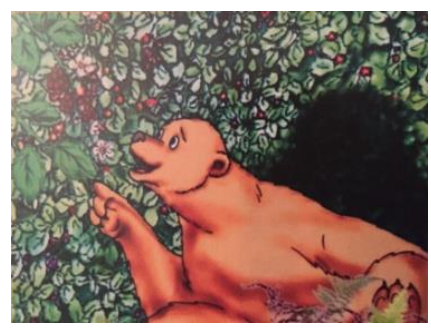

в)

Рис. 5. а), б) Кадры из фильма «Джинния Маймуна»; в) кадр из фильма «Сон в руку!»

Восточная сказка в руках талантливого аниматора Фирангиз Гурбановой превращается в особый мир с её особой интерпретацией этого сюжета.

В 2008 году на студии «Бирлик» автором создаётся фильм «Сон в руку!», который был снят по заказу Министерства Культуры для студии «Азанфильм». Для создания мультипликации этого фильма был приглашён грузинский художник Гела Берианидзе, работающий в компьютерной графике - анимации, что было востребовано в этом жанре того времени. С этим 
художником в последующих фильмах в соавторстве создаются и другие совместные творческие фильмы.

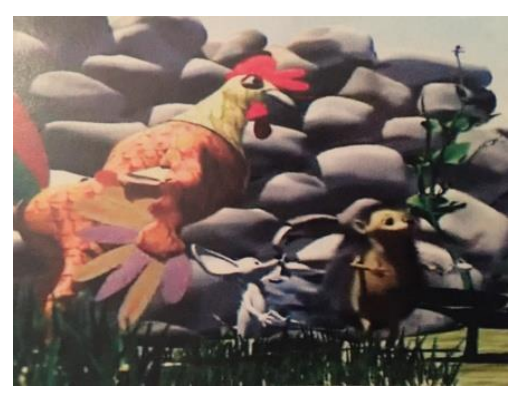

a)

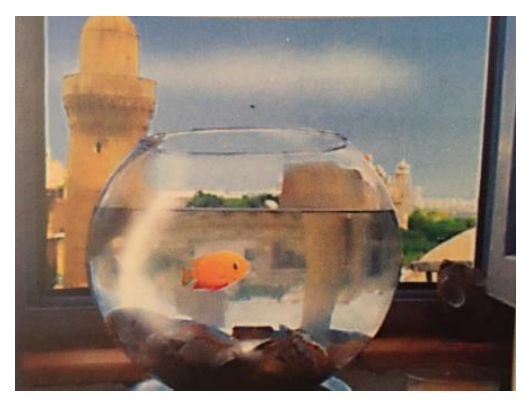

б)

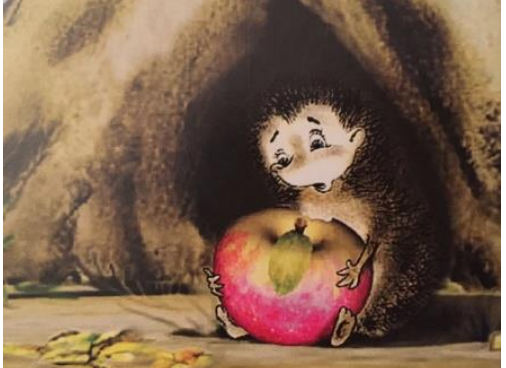

в)

Рис. 6. а) Кадр из фильма «Добрый ёж»; б) кадр из фильма «Зловредная муха»; в) кадр из фильма «Вкус доброты» (Джавид Ахадов)

«Добрый ёж» (2009) - так называется очередной фильм Фирангиз Гурбановой, который был одним из первых азербайджанских мультфильмов, снятых в технике 3D. В сюжете этой анимации был передан спор петуха и мышонка, пытающихся поделить горошек. Их спор решает умный ёж, который сажает зёрнышко горошка в землю, и которое потом вырастает в прекрасный стебель со стручками гороха, приумножающих это зёрнышко во много раз. Автор словно намекает о мире в этом фильме.

Министерство Культуры для студии «Мозалан» заказало новый фильм Фирангиз Гурбановой, который она назвала «Зловредная муха» (2011). Этот фильм удался благодаря творческому подходу режиссуры, которая была создана при помощи техники совмещения фотографии и компьютерной графики. Фильм «Зловредная муха» получил специальный приз жюри «За высокий профессионализм» на XVI Международном фестивале детского анимационного кино «Золотая рыбка» в Сочи (2011) и был показан в Праге на Форуме «Дни кино стран СНГ» (2012), а также на кинофестивале «Лучезарный ангел» в Москве (2012).

В семейном содружестве студии «Бирлик» с новой режиссурой и творческим видением заявил о себе сын Фирангиз Гурбановой - Джавид Ахадов, который поставил новый анимационный фильм «Вкус доброты» (2007). Он рассказывает зрителям о доброте и щедрости ежа.

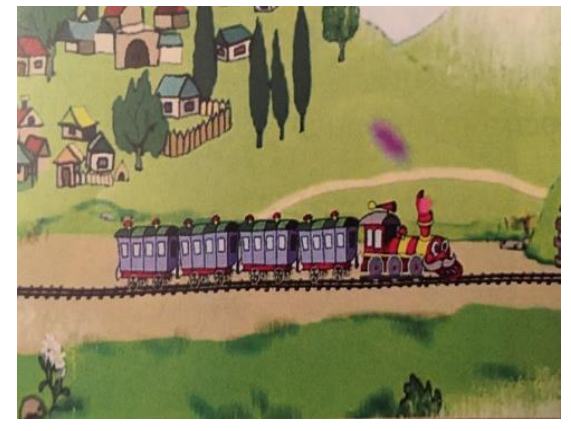

a)

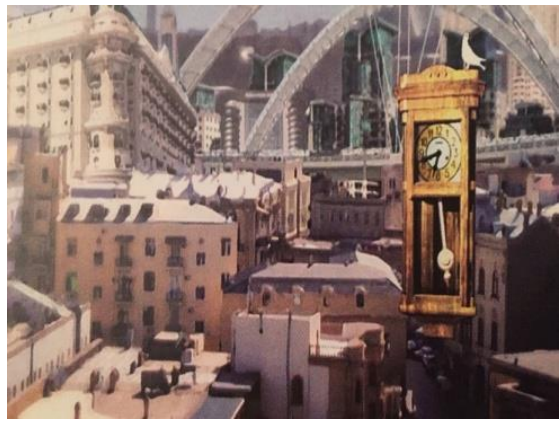

б)

Рис. 7. а) Кадр из фильма «Рисунок в небе» (Джавид Ахадов); б) кадр из фильма «Старинные часы» (Джавид Ахадов)

Другим мультфильмом Джавида Ахадова стал «Рисунок в небе» (2012). В нём повествуется о карандаше, которому мешает рисовать ластик. Этот фильм был показан на XVIII Фестивале короткометражных фильмов «Шлингель» в Германии (2013), на XXII Международном кинофоруме «Золотой Витязь» в России (2013), а также на XVIII Открытом российском фестивале анимационного кино в Суздале, Россия (2013).

Очередным фильмом студии «Бирлик» в лице режиссёра, постановщика, сценариста и аниматора Джавида Ахадова стал фильм «Старинные часы» (2014), который был показан на 
VIII международном кинофестивале «Вареш» в Иране (2015), XII фестивале «Крок»на Украине (2015), V Международном кинофестивале стран СНГ, Балтии и Грузии в Кыргызыстане (2015), XI Казанском международном фестивале мусульманского кино (2015), XVI международном фестивале анимации в Хиросиме (2016). «Старые часы» (2014) рассказывает о старом согнутом гвоздике и молоточке, которые уже не нужны хозяину мастерской. Желая быть полезными, они вместе решают починить старые часы, т.е. «оживить время». Благодаря им механизм старых часов заработал и вошёл в новую жизнь $[1$, c.151]. Этот фильм был удостоен награды от Союза кинематографистов Азербайджана (2015) и от Гильдии профессиональных режиссёров Азербайджана на фестивале «Золотая Пяри» (2015).

Фирангиз Гурбанова - заслуженный деятель искусств Азербайджана, является доцентом кафедры рисунка в Азербайджанской Государственной Академии Художеств, член жюри в международных кинофестивалях («Тофузи», 2009), а также руководит киностудией «Бирлик».

Её профессиональные фильмы разные по сюжету тематике, выполнению композиции и приёмам анимации. Начиная с 2007 года, в своих фильмах Фирангиз Гурбанова развивает лучшие методы компьютерной графики в этом жанре в своей киностудии «Бирлик», что делает её работы более успешными и интересными.

\title{
Литература
}

[1] Агамалиев Рашид. Азербайджанская анимация. Издательство «Peri film». Баку. 2018.

[2] Ибрагимов Эльдар. Искусство и мораль. Баку. Газета «Обозреватель». № 11. 2003.

[3] Салье М. (перевод и комментарии); Крачковский И. (редакция): Тысяча и одна ночь. Собрание сказок: в 8 т.Т.3. Повесть о Камар-аз-Замане и Будур. Москва: Терра. 2007.

\section{Azerbaijan Animation in the Work of the Frange Gurbanova, Its Symbolic Receptions in Studio "Birlik"}

\author{
Farida Mir-Bagirzade \\ Institute of Architecture and Art \\ of the National Academy of Sciences of Azerbaijan, Azerbaijan
}

\begin{abstract}
Summary. Azerbaijani animation began its creative development in 1936 and continues it in our modern time. Firangiz Gurbanova became one of the brightest personalities who contributed a large and bright page in this field. From 1988 to 2014, her major works include: "Make a dream" (1979), "Ginniya Maymuna" (1991), "Aquarium" (1983), "One Evening" (1985), "Mom on a Tree" (1986) , 4 films "Composition on the topic ..." (1989 - 1992); her son, Javid Akhadov, "Taste of Kindness" (2007), "Good Hedgehog" (2009), "Malicious Fly" (2011), "Drawing in the Sky" (2012), "Old Clock" (2014). In her animated films, she was one of the first in Azerbaijani cinema that was able to combine animation with feature films. For the first time in her cartoons, mobile graphics techniques and image highlighting with color filters were used. Firangiz Gurbanova is an Honored Art Worker of Azerbaijan, an Associate Professor of the Drawing Department at the Azerbaijan State Academy of Arts, a jury member at international film festivals (Tofuzi, 2009), and also runs the Birlik Film Studio. Her professional films are different in subject matter, subject matter, composition, and animation techniques. Since 2007, in his films, Firangiz Gurbanova develops the best methods of computer graphics in this genre in his film studio "Birlik", which makes her work more successful and interesting.
\end{abstract}

Keywords: animation, lighting, genre, plot, composition, jury, prize, creativity, search, graphics, painting, watercolor, computer, methods, techniques

\section{References}

[1] Agamaliyev Rashid. (2018). Azerbaydjanskaya animatsiya. Izdatelstvo «Peri film». Baku. 2018. 400 p.

[2] Ibragimov Eldar. (2003). Iskusstvo i moral. Baku. Qazeta «Obozrevatel». № 11. 2003. 4 p.

[3] Salye M. (perevod I kommentarii); Krashkovskiy I. (redaksiya). (2007): Tisyasha I odna noch. Sobraniye skazok: v 8 t. T.3. Povest o Kamar-az-Zamane I Budur. Moskva: Terra. 2007. 120 p.

Культура и технологии, Том 4, № 1 